(C) 2016 IEEE. Personal use of this material is permitted. Permission from IEEE must be obtained for all other uses, in any current or future media, including reprinting/republishing this material for advertising or promotional purposes, creating new collective works, for resale or redistribution to servers or lists, or reuse of any copyrighted component of this work in other works. 


\title{
ADRC-based Model Predictive Current Control for PMSMs fed by Three-phase Four-switch Inverters
}

\author{
Topics: Motor Drives and Motor Control
}

\begin{abstract}
An automatic disturbances rejection control (ADRC)-based model predictive current control (MPCC) strategy is developed for permanent magnet synchronous motors (PMSMs) fed by three-phase four-switch inverters. The model of a PMSM fed by a three-phase four-switch inverter is built firstly. Then the ADRC and MPCC are respectively designed. The resultant ADRC-based MPCC PMSM drive has fault-tolerant effective. On the other hand, compared with PI-based MPCC PMSM drive, it possesses better dynamical response behavior and stronger robustness in the presence of variation of load torque. The simulation results validate the feasibility and effectiveness of the proposed scheme.
\end{abstract}

\section{INTRODUCTION}

One of the most common types of potential failures in an electrical drive system is the breakdown of one transistor in the voltage source inverter (VSI), which may cause unacceptably high pulsating torque and consequently the drive system has to be interrupted. To solve the problem, a common method is to design a fault-tolerant inverter topology plus an effective control strategy that is able to manage the drive system during the inverter fault. Over the past years, several reconfigurations of inverter topologies for overcoming its faults have been developed. One of them is named as extra-leg split capacitor scheme[1]. This topology enables the electrical machine to still operate in a three-phase mode during the fault and thus is referred to as three-phase four-switch mode which is employed in this paper.

For permanent magnet synchronous motor (PMSM) drive system, model predictive current control (MPCC) [2] is an emerging control strategy. Its main objective is to control instantaneous stator current with high accuracy in a transient interval as short as possible and thus plays an important role to ensure the quality of the torque and speed control. MPCC adopts the principle of model predictive control (MPC) [3-4] and can provide higher dynamic performance and lower stator current harmonic.

For a conventional PI-based MPCC PMSM drive system, its speed regulator employs the algorithm of PI. In general, PI may perform well under certain operating conditions, but degrade dynamic performance under other operating conditions when disturbances arise. To improve the robustness of PI, several techniques have been proposed in recent years. In these techniques, automatic disturbances rejection control (ADRC) is an effective and practical one, which was firstly proposed by Han [5]. The key of ADRC is to reformulate the problem by lumping various known and unknown quantities that affect the system performance into total disturbance [6]. And the total disturbance can be actively estimated and then rejected. Due to being independent of the accurate model of the system, it is very robust against disturbances. For this reason, we propose replacement of PI with ADRC in our research.

For three-phase four-switch inverter in PMSM drive systems, in order to improve dynamic performance and system robustness, a novel ADRC-based MPCC strategy is proposed in our research.

\section{DYNAMIC MODEL OF PMSMS FED BY THREE-PHASE FOUR-SWITCH INVERTER}

As for three-phase PMSM drive, assume that one transistor is broken down in the inverter leg corresponding phase $a$. In this case, we adopt the three-phase four-switch inverter as shown in Fig.1. 


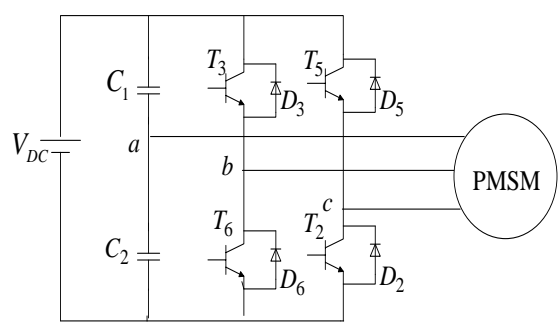

Fig.1 Three-phase four-switch inverter and PMSM drive

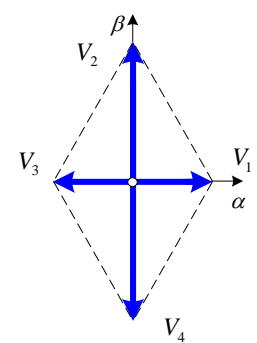

Fig.2 The layout of voltage space vectors

As for Fig.1, three-phase stator voltage in $a b c$-system is given by:

$$
\left\{\begin{array}{l}
u_{a}=V_{D C}\left(1-S_{b}-S_{c}\right) / 3 \\
u_{b}=V_{D C}\left(-0.5+2 S_{b}-S_{c}\right) / 3 \\
u_{c}=V_{D C}\left(-0.5-S_{b}+2 S_{c}\right) / 3
\end{array}\right.
$$

where $u_{a}, u_{b}$ and $u_{c}$ are stator voltages, $V_{D C}$ is DC bus voltage, and $S_{i}(i=\mathrm{b}, \mathrm{c})$ the upper switch state of one of two legs. $S_{i}=1$ or $S_{i}=0$ when upper switch is on or off as shown in Fig.1. The combination of $S_{b}$ , $S_{c}$ may form four switching states corresponding four voltages $V_{1}, V_{2}, V_{3}, V_{4}$ as shown in Fig. 2.

Consider surface-mounted PMSM. The mathematical model in $\alpha \beta$-system is expressed as follows

$$
\left\{\begin{array}{l}
i_{\alpha}=\left(-R_{s} i_{\alpha}+\psi_{f} \omega_{r} \sin \left(p \theta_{r}\right)+u_{\alpha}\right) / L \\
\dot{i}_{\beta}=\left(-R_{s} i_{\beta}-\psi_{f} \omega_{r} \cos \left(p \theta_{r}\right)+u_{\beta}\right) / L
\end{array}\right.
$$

where $i_{\alpha}, i_{\beta}, u_{\alpha}, u_{\beta}, \psi_{\alpha}, \psi_{\beta}$ are $\alpha$ and $\beta$ axis stator current, stator voltage, and stator flux, respectively. $L$ is the stator-winding inductance, $R_{\mathrm{S}}$ the stator winding resistance. $\psi_{f}$ the permanent magnet flux, and $\theta$ and $\omega_{r}$ are the measured rotor angular displacement and speed, respectively .

By Newton's law, the electromagnetic torque equation can be written as

$$
J \dot{\omega}_{r}=T_{e}-T_{l}-B_{m} \omega_{r}-T_{f}
$$

where $J, T_{\mathrm{e}}, T_{1}, B_{\mathrm{m}}$ and $T_{\mathrm{f}}$ are the inertia of moment, electromagnetic torque, exogenous load torque, viscous friction coefficient and coulomb friction torque, respectively and $p$ is the number of pole pairs.

\section{DESIGN OF ADRC-BASED MPCC FOR PMSM DRIVE SYSTEMS FED BY THREE-PHASE FOUR-SWITCH INVERTERS}

The diagram of ADRC-based MPCC system proposed is shown in Fig.3.

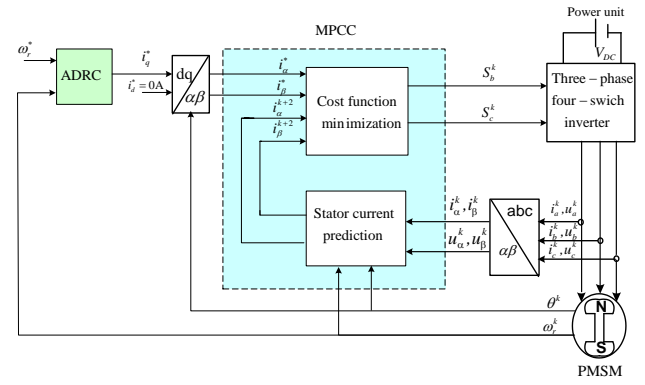

Fig.3 ADRC-based MPCC for PMSM

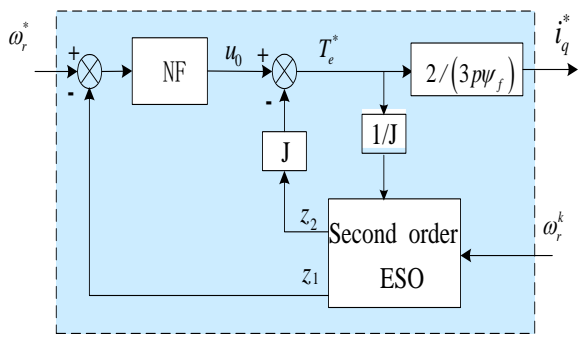

Fig.4 Diagram of ADRC

\section{A. ADRC design}

Fig. 4 shows the diagram of ADRC, which consists of an extended state observer (ESO) and a nonlinear function (NF). The ESO is used to estimate the unmeasured state and the real action of the unknown disturbances to build a solid base for better performance and disturbances compensation. The $\mathrm{NF}$ is used to synthesize the control action.

Let

$x_{1}=\omega_{r}, y=x_{1}$ 
The state space equation of (3) is yielded as following

$$
\left\{\begin{array}{l}
\dot{x}_{1}=-B_{m} x_{1} / J-\left(T_{l}+T_{f}\right) / J+T_{e} / J \\
y=x_{1}
\end{array}\right.
$$

And the total disturbance $f(t)$ is defined as

$$
f(t)=-B_{m} \omega_{r} / J-\left(T_{l}+T_{f}\right) / J
$$

Treating $f(t)$ as an augmented variable $x_{2}$, i.e., $x_{2}=f(t)$. and letting $\dot{f}(t)=g(t)$, with $g(t)$ unknown, one can rewrite the state space expression in (5) as

$$
\left\{\begin{array}{l}
\dot{x}_{1}=x_{2}+T_{e} / J \\
\dot{x}_{2}=g(t)
\end{array}\right.
$$

Now we construct a second-order state observer, denoted as the ESO, in the form of

$$
\left\{\begin{array}{l}
e=\omega_{r}-z_{1} \\
\dot{z}_{1}=z_{2}-\beta_{1} f a l\left(e, a_{1}, \delta_{1}\right)+T_{e} / J \\
\dot{z}_{2}=-\beta_{2} f a l\left(e, a_{2}, \delta_{2}\right)
\end{array}\right.
$$

where $\beta_{1}, \beta_{2}, \alpha_{1}, \alpha_{2}$ and $\delta_{1}$ are positive parameters, $f a l(x, a, \delta)$ is a nonlinear function defined as

$$
f a l(x, a, \delta)= \begin{cases}x \cdot \delta^{a-1}, & |x| \leq \delta \\ \operatorname{sign}(x) \cdot|x|^{a}, & |x|>\delta\end{cases}
$$

By canceling the influence of total disturbance $f(t)$ using $z_{2}$, ADRC actively compensates for $f(t)$ in real time. The reference torque in Fig. 4 is designed as following,

$$
T_{e}^{*}=u_{0}(t)-J z_{2}
$$

where $u_{0}(t)$ is the output of NF defined as

$$
u_{0}(t)=\beta_{3} f a l\left(\omega_{r}^{*}-z_{1}, a_{3}, \delta_{3}\right)
$$

\section{B. Model predictive current control}

For conventional MPCC, the minimum cost function is such chosen that both $i_{\alpha}$ and $i_{\beta}$ are as close as possible to their reference values. Its definition is as follows

$$
\begin{aligned}
& \min .\left\{g_{i}\right\}=\left|i_{\alpha}^{*}-i_{\alpha}^{k+1}\right|+\left|i_{\beta}^{*}-i_{\beta}^{k+1}\right| \\
& \text { s.t. } V_{i} \in\left\{\begin{array}{llll}
V_{1} & V_{2} & V_{3} & V_{4}
\end{array}\right\}, i=1, \cdots, 4
\end{aligned}
$$

where the current predictions $i_{\alpha}^{k+1}$ and $i_{\beta}^{k+1}$ at $(k+1) t h$ instant can be expressed as the following

$$
\left\{\begin{array}{l}
i_{\alpha}^{k+1}=i_{\alpha}^{k}+T_{s}\left(-R_{s} i_{\alpha}^{k}+\psi_{f} \omega_{r}^{k} \sin \left(p \theta_{r}^{k}\right)+u_{\alpha}^{k}\right) / L \\
i_{\beta}^{k+1}=i_{\beta}^{k}+T_{s}\left(-R_{s} i_{\beta}^{k}-\psi_{f} \omega_{r}^{k} \cos \left(p \theta_{r}^{k}\right)+u_{\beta}^{k}\right) / L
\end{array}\right.
$$

To compensate for the computation delay, the cost function in (12) is changed to (14) as below

$$
\begin{aligned}
& \min .\left\{g_{i}\right\}=\left|i_{\alpha}^{*}-i_{\alpha}^{k+2}\right|+\left|i_{\beta}^{*}-i_{\beta}^{k+2}\right| \\
& \text { s.t. } V_{i} \in\left\{\begin{array}{llll}
V_{1} & V_{2} & V_{3} & V_{4}
\end{array}\right\}, i=1, \cdots, 4
\end{aligned}
$$

\section{Simulation AND ANALYSIS}

The designed control system in Fig. 3 is implemented in Matlab. The parameters of PMSM: $R_{\mathrm{S}}$ is $2.875 \Omega, L$ is $0.0085 \mathrm{H}, \psi_{f}$ is $0.175 \mathrm{~Wb}, p$ is $1, V_{\mathrm{DC}} 350 \mathrm{~V}, n_{N}$ is $3000 \mathrm{rpm}, J$ is $0.0008 \mathrm{Kg} \cdot \mathrm{m}^{2}, T_{\mathrm{n}}$ is $3 \mathrm{~N} . \mathrm{m}$, $T_{\mathrm{f}}$ is 0 and $B_{\mathrm{m}}$ is $0.001 \mathrm{Nms}$.

\section{A. Fault-tolerant effect}

Figs.5 and 6 show their comparison results. Comparing Fig.5 with Fig.6, it can be seen that, for the 
PMSM system fed by unhealthy inverter, it has fault-tolerant effective and its speed and torque could be regulated in a satisfactory manner and its performance is almost as good as the PMSM system fed by healthy inverter.

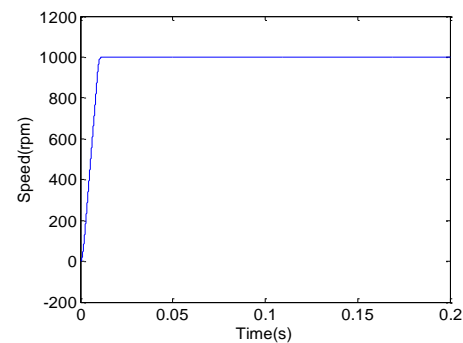

(a) Rotor speed response

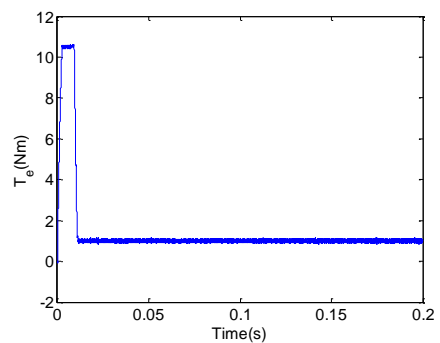

(b) Torque response

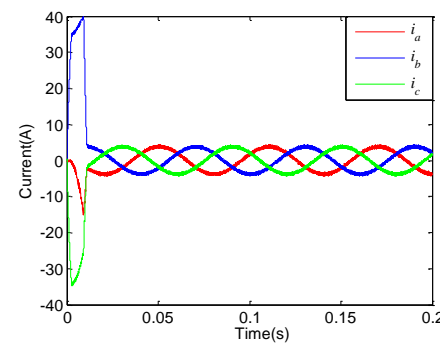

(c) Stator current $i_{a}, i_{\mathrm{b}}$ and $i_{\mathrm{c}}$

Fig.5 Dynamic response for PMSM fed by three-phase six-switch inverter (i.e. healthy inverter)

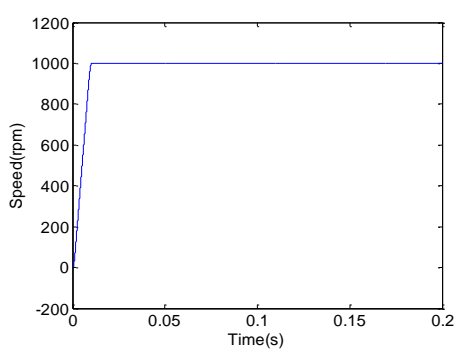

(a) Rotor speed response

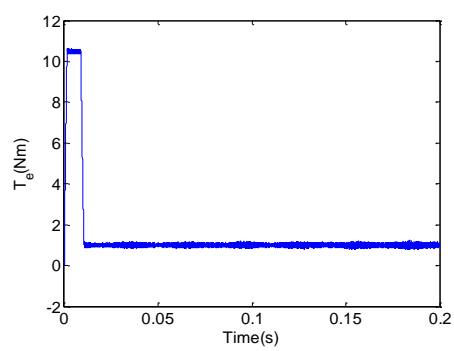

(b) Torque response

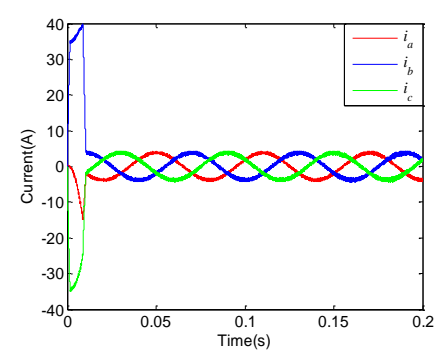

(c) Stator current $i_{a}, i_{\mathrm{b}}$ and $i_{\mathrm{c}}$

Fig.6 Dynamic response for PMSM fed by three-phase four-switch inverter (i.e. unhealthy inverter)

\section{B. Robustness}

Two systems are compared, which correspond to the PI-based MPCC and ADRC-based MPTC PMSM systems, respectively. Except their distinct speed regulators (i.e. PI and ADRC), two systems have completely identical structure and parameters of MPCC.

\section{1) Comparison of anti-interference of load}

To make a fair comparison of both control schemes, the parameters of PI for PI-based MPCC PMSM system are adjusted such that PI-based MPCC system has almost identical overshoot and settling time with ADRC-based one.

Figs.7 and 8 show their dynamical responses. Comparing Fig.7(a) with Fig.8(a), it can be seen that, for ADRC-based MPCC PMSM system, its speed can sharply adapt to the change of external load change in a satisfactory manner, and its capable of accommodating the challenge of load disturbance is superior to PI-based one's.

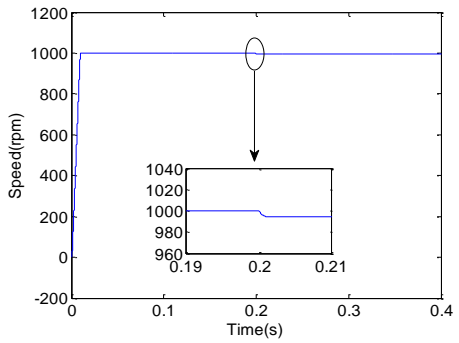

(a) Rotor speed response

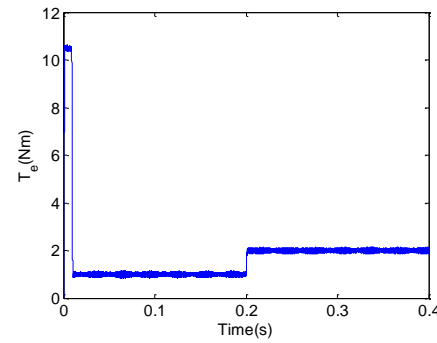

(b) Torque response

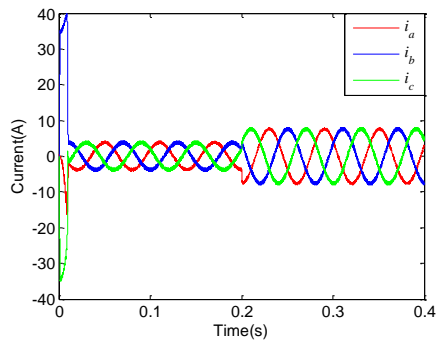

(c) Stator current $i_{a}, i_{b}$ and $i_{c}$ 
Fig.7 Dynamic response of PI-based MPCC scheme for PMSM fed by an unhealthy inverter

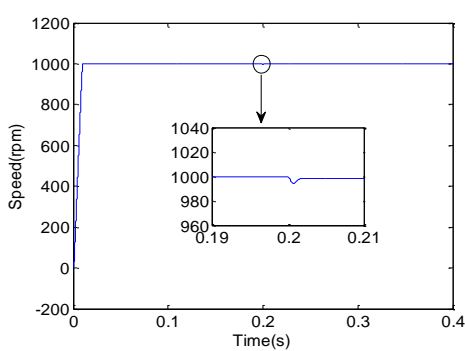

(a) Rotor speed response

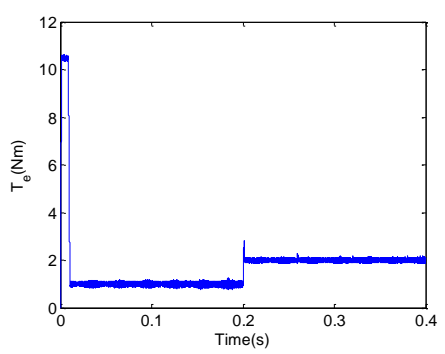

(b) Torque response

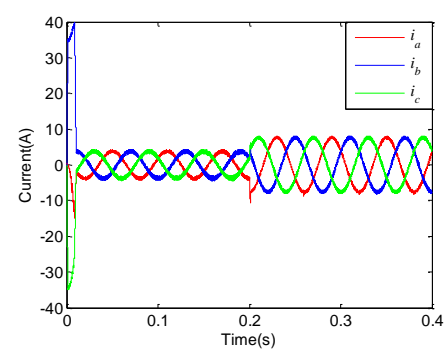

(c) Stator current $i_{a}, i_{b}$ and $i_{c}$

Fig.8 Dynamic response of ADRC-based MPCC scheme for PMSM fed by an unhealthy inverter

\section{2) Comparison of dynamical response}

To make a fair comparison, the parameters of PI are adjusted such that PI-based MPCC system has almost identical ability of anti-load disturbance with ADRC-based one. Fig.9 shows their speed responses. From Fig.9, it can be seen that, compared with PI-based MPCC PMSM system, the overshoot and settling time of ADRC-based one are obviously smaller and thus its dynamical response is superior.

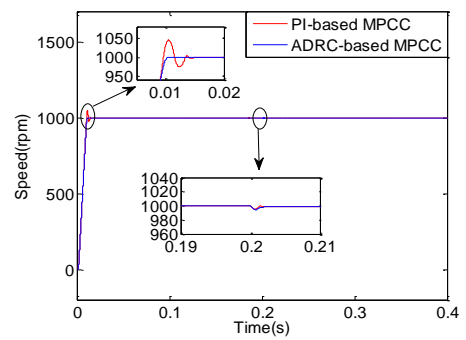

Fig.9 Speed response comparison between PI-based and ADRC-based MPCC schemes

\section{CONCLUSION}

The designed ADRC-based MPCC PMSM fed by an unhealthy inverter is fault-tolerant effective, and its speed \& torque could be regulated in a satisfactory manner. On the other hand, ADRC-based MPCC strategy can guarantee the ability to achieve two objectives simultaneously: satisfactory dynamical response and strong disturbance rejection, whereas PI-based one can guarantee only one of the two objectives.

\section{REFERENCES}

[1] K. Zhao, Q. T. An, L. Sun, and W. Ye, "Fault-tolerant inverter permanent synchronous motor position sensorless control system," Ėlectric machine and control, vol.14,no.4,pp. 25-30, 2012.

[2] H. Young, M. Perez, and J. Rodriguez, et al, "Assessing finite-control-set model predictive control: a comparison with a linear current controller in two-level voltage source inverters," IEEE Industrial Electronics Magazine, vol.8,no.1, pp. 44-52, 2014.

[3] T. A. Geyer, G. Papafotiou, and M. Morari, "Model predictive direct torque control-Part I: Concept, algorithm, and analysis," IEEE Transactions on Industrial Electronics, vol.56,no.6, pp. 1894-1905, 2009.

[4] Q. F. Teng, J. Y. Bai, J. G. Zhu, and Y. G. Guo, "Sensorless model predictive torque control using sliding-mode model reference adaptive system observer for permanent magnet synchronous motor drive systems," Control Theory \& Applications, vol.32, no.2, pp. 150-161, 2015.

[5] J. Q. Han, “Auto disturbances rejection control technique," Frontier Science, vol.1,no.1, pp. 24-31, 2007.

[6] J. Q. Han, "From PID to active disturbance rejection control," IEEE transactions on Industrial Electronics, vol.56,no.3, pp. 900-906, 2009. 


\section{APPENDIX}

This work was supported by National Natural Science Foundation of China (No. ****). 